\title{
The effects of obesity, smoking, and excessive alcohol intake on healthcare expenditure in a comprehensive medical scheme
}

\author{
R Sturm, ${ }^{1} \mathrm{PhD} ; \mathbf{R}$ An, ${ }^{2} \mathrm{PhD} ; \mathbf{J}$ Maroba,${ }^{3} \mathrm{BSc} ;$ D Patel, ${ }^{3}$ MMed (Paeds) \\ ${ }^{1}$ RAND Corporation, Santa Monica, California, USA \\ ${ }^{2}$ Department of Kinesiology and Community Health, University of Illinois at Urbana-Champaign, Champaign, Illinois, USA \\ ${ }^{3}$ Discovery Vitality, Johannesburg, South Africa
}

Corresponding author: R Sturm (sturm@rand.org)

\begin{abstract}
Background. Health risks such as tobacco use, excessive alcohol consumption and unhealthy body weight contribute to the development of chronic health problems.

Objective. To estimate the associations of tobacco use, excessive alcohol consumption and obesity with healthcare expenditure and chronic diseases among South Africans on a comprehensive medical scheme.

Methods. We performed a cross-sectional analysis of health survey and medical claims data for 70000 South Africans during 2010.

Results. Moderately obese individuals, with a body mass index (BMI) of $30-35 \mathrm{~kg} / \mathrm{m}^{2}$ averaged R2 300 (11\%) higher annual medical expenditure in the year 2010 than never-smokers with a BMI $<30 \mathrm{~kg} / \mathrm{m}^{2}$. This increase is comparable with being a current or past smoker (expenditure increase by R2 600;13\%). Severely obese individuals (BMI $\left.>35 \mathrm{~kg} / \mathrm{m}^{2}\right)$, however, had increased healthcare costs of R4 $400(23 \%$ increase). This exceeds the difference between a 40 - and a 50-year-old (increase of R3 200). Being overweight or excessive consumption of alcohol was not significantly associated with medical expenditures. Absolute and relative excess expenditures associated with these health risks are higher among older individuals. In the 54 - 69-year age group, estimated additional expenses were R6 200 for smoking (20\% increase over never-smokers with BMI $\left.<30 \mathrm{~kg} / \mathrm{m}^{2}\right)$, R6 600 for moderate obesity (21\%) and R15 800 for severe obesity (51\% increase). Overweight or heavy drinking was not statistically significantly associated with healthcare expenditure.

Conclusion. Obesity and tobacco use are associated with significantly increased healthcare expenditure. Severe obesity doubles these excess costs.

S Afr Med J 2013;103(11):840-844. DOI:10.7196/SAMJ.7260
\end{abstract}




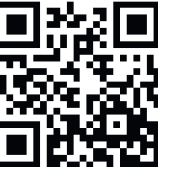

Health risks such as obesity, smoking and excessive alcohol intake are common among South Africans (SAs) and much of the disease burden can be attributed to these lifestyle risk factors. ${ }^{[1]}$ All are potentially modifiable through smoking cessation programmes, taxation and regulation of tobacco and alcohol products, or programmes that encourage healthy diets or increase physical activity. The prevalence of chronic diseases, including diabetes and certain cancers, has increased in SA and is set to continue to rise unless there are active countermeasures. ${ }^{[2-4]}$ These chronic health conditions, in turn, are thought to be drivers of increasing healthcare expenditures.

Understanding the relative contributions of risk factors to poor health allows better targeting of health promotion programmes to make prevention efforts more cost-effective. Health promotion activities are traditionally focused on smoking and excessive alcohol intake, whereas overweight and obesity have become prominent in recent policy debates. Obesity rates are increasing rapidly among SA adolescents, setting the stage for an increase in obesity-related chronic conditions over the following decades. ${ }^{[5]}$

Among SA adults, the privately insured account for about $17 \%$ and enjoy a higher income and greater access to medical care than those who are uninsured.

While obesity and overweight are grouped together, the health and healthcare consequences differ dramatically. US studies have shown little or no effect of overweight on healthcare cost or mortality, yet large effects of higher levels of obesity. ${ }^{\left[{ }^{[, 7]}\right.}$ Hence, we distinguish between overweight and moderate and severe obesity in this analysis.

\section{Objective}

To compare the associations between obesity, smoking, excessive alcohol intake and healthcare utilisation and the prevalence of chronic conditions among adults contributing to a private medical scheme.

\section{Methods}

The data were drawn from members of a comprehensive Discovery Health medical plan who were also enrolled in the Vitality Health promotion programme. We used data from an online health risk assessment (HRA) fielded in 2010 and healthcare costs data for 2010. The HRA collects data on selected health risks, including smoking, alcohol consumption, and body height and weight, and is fielded as part of the health-promotion programme (similar data are not available for plan members not enrolled in Vitality Health). The assessment has had a response rate of about $35 \%$. Survey responses completed by adults aged 18 years and older in 2010 were merged to their medical claims of the same year. The total sample was 74504 adults, half of whom were female. The 1651 women who reported being pregnant were excluded. In addition, 3473 respondents provided no response for one or more key variables (i.e. smoking status, alcohol consumption, and body height or weight) and were excluded in the multivariate analysis, resulting in a total analytic sample of 69380 . A separate analysis was conducted for individuals aged $54-69$ years $(n=8765,13 \%$ of the total sample). The Human Subjects Protection Committee at RAND Corporation reviewed and approved the research plan.

The dependent variables were healthcare expenditure in 2010 (both total expenditure and expenditure by inpatients and outpatients) and a count of the presence of 17 common chronic conditions derived from diagnoses on claims (including hypertension, hypercholesterolaemia, liver disease, pulmonary disease, diabetes).
The main explanatory variables were: $(i)$ body mass index (BMI) according to the standard categories: underweight $\left(\mathrm{BMI}<18.5 \mathrm{~kg} / \mathrm{m}^{2}\right)$, normal weight $\left(18.5 \leq \mathrm{BMI}<25 \mathrm{~kg} / \mathrm{m}^{2}\right)$, overweight $\left(25 \leq \mathrm{BMI}<30 \mathrm{~kg} / \mathrm{m}^{2}\right)$, moderately obese $\left(30 \leq \mathrm{BMI}<35 \mathrm{~kg} / \mathrm{m}^{2}\right)$, and severely obese (BMI $\geq 35 \mathrm{~kg} / \mathrm{m}^{2}$ ); (ii) excessive alcohol intake (defined as having $\geq 3$ drinks/ day); and (iii) smoking (being a current or past regular smoker - grouped together). There was no information on lifetime duration of smoking or weight history. Other explanatory variables included any alcohol consumption, age as a linear spline with knots at age 30, 40, 50 and 60 years, and gender.

BMI was calculated from self-reported height and weight. Selfreporting tends to lead to understatement of weight (more so for women) and overstatement of height (more so for men). ${ }^{[8]}$ The underreporting of weight increases with weight and prevalence at the same cut-off points are therefore lower than if BMI was calculated from an independent measurement. Reporting accuracy in this SA population is unknown, but in the US, using the 2007/08 National Health and Nutrition Examination Survey, an objective cut-off point of 30 would correspond to a cut-off point of 28.7 for men and 28.4 for women. ${ }^{\left[{ }^{[9]}\right.}$ We only used this adjustment for comparative purposes as its applicability for populations outside the US is unclear. Selfreporting biases are not limited to height or weight, as smoking or alcohol consumption also tends to be underreported.

The bivariate association between BMI and healthcare expenditure was illustrated by plotting a semi-parametric local polynomial estimate of expenditure on BMI. These curves are drawn for BMIs between 18.5 and 35 , because there are few observations in the underweight or severe obesity category for local estimates. In the multivariate analyses, ordinary least squares (OLSs) of raw expenditure on explanatory variables were conducted, using the full dataset (this model estimates adjusted averages for each group instead of local estimates at every BMI point). OLSs provide unbiased estimates and avoids statistical complications associated with retransformation (e.g. estimates of log-models) ${ }^{[10]}$ Multi-part models may improve estimation efficiency, ${ }^{[11]}$ but our sample was large enough to provide precise estimates even in the absence of multi-part models. All statistical analyses were conducted using Stata SE (version 12).

Sensitivity analyses were performed to assess the robustness of the qualitative conclusions across sample classifications and alternative model specifications. Separate models were estimated for different age groups and for men only and women only. The analyses on members on different (less comprehensive) health plans were also repeated and alternative statistical models (e.g. two-part model and $\log$ transformation of expenditure) were used.

\section{Results}

Table 1 depicts descriptive sample statistics from men and women. The average BMI in 2010, based on self-reported height and weight, was $27.1 \mathrm{~kg} / \mathrm{m}^{2}$ for adult men and $25.6 \mathrm{~kg} / \mathrm{m}^{2}$ for adult women, corresponding to an obesity prevalence of $24.4 \%$ and $18 \%$, respectively. Just over $6 \%$ of men and women were severely obese (BMI $\geq 35 \mathrm{~kg} / \mathrm{m}^{2}$ ). Underweight (BMI $<18.5 \mathrm{~kg} / \mathrm{m}^{2}$, results not shown) was rare among women and extremely rare among men (only 148 men). About one-third of the sample comprised a current or prior regular smoker and, while the majority drank some alcohol, $\geq 3$ drinks/day was uncommon.

Fig. 1 illustrates the association between BMI and healthcare expenditure in three parts: total expenditure, outpatient expenditure only, and inpatient expenditure only. A small reduction in total expenditure is present in the low BMI range and the reduction 
Table 1. Descriptive statistics ${ }^{*,+}$

\begin{tabular}{|c|c|c|}
\hline & $\begin{array}{l}\text { Men }(N=35880) \\
\text { mean }( \pm S D)\end{array}$ & $\begin{array}{l}\text { Women }(N=35322) \\
\text { mean }( \pm \mathrm{SD})\end{array}$ \\
\hline Age (years) & $41.4( \pm 11.2)$ & $39.7( \pm 10.8)$ \\
\hline BMI $\left(\mathrm{kg} / \mathrm{m}^{2}\right)$ & $27.7( \pm 4.64)$ & $25.6( \pm 5.6)$ \\
\hline \multicolumn{3}{|l|}{$\geq 25-<30$ (overweight) } \\
\hline$\geq 30-<35$ (obese) & $24.4( \pm 42.9)$ & $18.0( \pm 38.4)$ \\
\hline$\geq 35$ (severely obese) & $6.4( \pm 24.6)$ & $6.5( \pm 24.8)$ \\
\hline Current or past regular smoker & $39.3( \pm 48.8)$ & $31.9( \pm 46.6)$ \\
\hline Alcohol consumption & $75.9( \pm 42.7)$ & $62.0( \pm 48.5)$ \\
\hline$\geq 3$ drinks/day (heavy drinking) & $1.1( \pm 10.6)$ & $0.3( \pm 5.4)$ \\
\hline \multicolumn{3}{|l|}{ Healthcare expenditure (ZAR) } \\
\hline Total & $18605( \pm 43557)$ & $22845( \pm 37288)$ \\
\hline Outpatient & $12768( \pm 23051)$ & $15994( \pm 22769)$ \\
\hline Inpatient & $5837( \pm 31974)$ & $6851( \pm 24114)$ \\
\hline
\end{tabular}

seems more pronounced for outpatient expenditure, which reaches its minimum in a BMI range of $24-25 \mathrm{~kg} / \mathrm{m}^{2}$. A constant rise in expenditure is observed for BMIs $>25 \mathrm{~kg} / \mathrm{m}^{2}$ and this increasing trend is accelerated for BMIs $\geq 30 \mathrm{~kg} / \mathrm{m}^{2}$ for inpatient costs. We excluded BMIs in the range of underweight and severe obesity due to the insufficient sample size for this type of analysis.

Table 2 depicts results from multivariate analyses for each BMI group and for three other risk factors: ageing, current or past smoking, and excessive alcohol intake ( $\geq 3$ drinks/day). Expenditure in people aged 50 years was on average R3 204 higher than in people aged 40 years, with almost all the difference due to additional outpatient services and with no significant effect on inpatient costs. A 10-year age difference also predicted an additional 27 chronic medical problems (or 27 new conditions among 100 people). Severe obesity had an even larger effect on medical expenditures and healthcare costs: an increase of R4 425 per person, split between inpatient and outpatient, and an incidence of an additional 70 chronic conditions per 100 severely obese individuals (that would not occur among similar individuals in the normal weight range. With total expenditure averaging R20 000 for never-smokers with a BMI $<30 \mathrm{~kg} / \mathrm{m}^{2}$, a R4 425 increase corresponds to a $22 \%$ increase. The effect of moderate obesity was only half of that (R2 238 increase, 11\%). Overweight had no effect on healthcare expenditures compared with normal weight.
Smoking (both current and previous) had an effect on costs that was similar to moderate obesity (R2 596, 13\% increase), but it had a smaller effect on chronic conditions. Heavy drinkers used fewer medical services despite having more chronic conditions.

Table 3 reveals the analysis for individuals aged 54 - 69 years, to parallel a US study. ${ }^{[6]}$ This age group accounted for $13 \%$ of our full dataset, resulting in larger standard errors. With total expenditure averaging around R31 000 for never-smokers with a BMI $<30 \mathrm{~kg} / \mathrm{m}^{2}$ in this age group in 2010, the estimated excess costs of moderate obesity (R6 639) correspond to a $21 \%$ increase and for severe obesity (R15 835) to a $51 \%$ increase. Smoking was associated with excess costs of R6 195 (20\% increase). Overweight has no significant association with healthcare costs. As there were too few individuals with heavy alcohol intake to provide meaningful estimates, results for this variable are not shown.

The sensitivity analyses found the qualitative results (not shown) to be fairly consistent across different subgroups (by age, gender and type of health plan) and model specifications (OLS v. two-part model), except for the underweight individuals and individuals aged $<30$ years. Moderate obesity was associated with an increase in healthcare $51 \%$, and smoking $8-20 \%$. The exceptions were individuals aged $<30$ years for whom there was no significant association between obesity, smoking or excessive alcohol consumption and healthcare expenditures. Dependent upon sample stratification, expenditure by $10-24 \%$, severe obesity 22 - the healthcare expenditure among the underweight population ranged from a small reduction to a large increase (the latter among male $<40$ years). Because average healthcare costs increase with age, the absolute magnitude of the excess costs of poor health habits were higher for older individuals (and correspondingly smaller for younger individuals) than the population effects in Table 2. Moreover, the relative increase was largest among people in their 50 s and 60s.

\section{Discussion}

This study is the first to provide data on the relationship between the levels of overweight and obesity, smoking, and excessive alcohol intake and medical expenditures among South Africans on a comprehensive medical insurance scheme. Across the adult population, obesity had a substantial effect on healthcare expenditure and there were large differences in expenditure by degree of obesity. Compared with individuals in the normal or overweight range, severely obese individuals used 23\% more, and moderately obese individuals $11 \%$ more medical services, which is similar to the group of current or past smokers.

The results are based on cross-sectional observational data and self-reported health risks. The results therefore do not show the causal, but rather the associated flow from risks to costs. Reverse causality (i.e. healthcausing risk factors) is less of an issue for obesity or smoking than it would be for physical activity because injuries and illness are a direct cause of reduced activity levels, but it will exist for some individuals (e.g. weight gain caused by certain medications). Underweight can be a consequence of severe illness, and often is a late stage of terminal conditions, which may explain why estimates for underweight are very sensitive to sample selection.

Physical activity and diet that can have independent health effects are unmeasured variables correlated with obesity. Empirically, it is difficult to disentangle these factors because activity and diet are very hard to measure and we had no meaningful measures for our population. Physical activity and diet are the upstream health behaviours that can be targeted, whereas BMI is an outcome of energy balance and is not a directly modifiable health behaviour. This study used self-reported height and weight, which generally underestimates BMI. This implies that our prevalence of severe obesity was lower than in objectively measured data, whereas estimated effects are larger than if objectively measured BMI were used. 

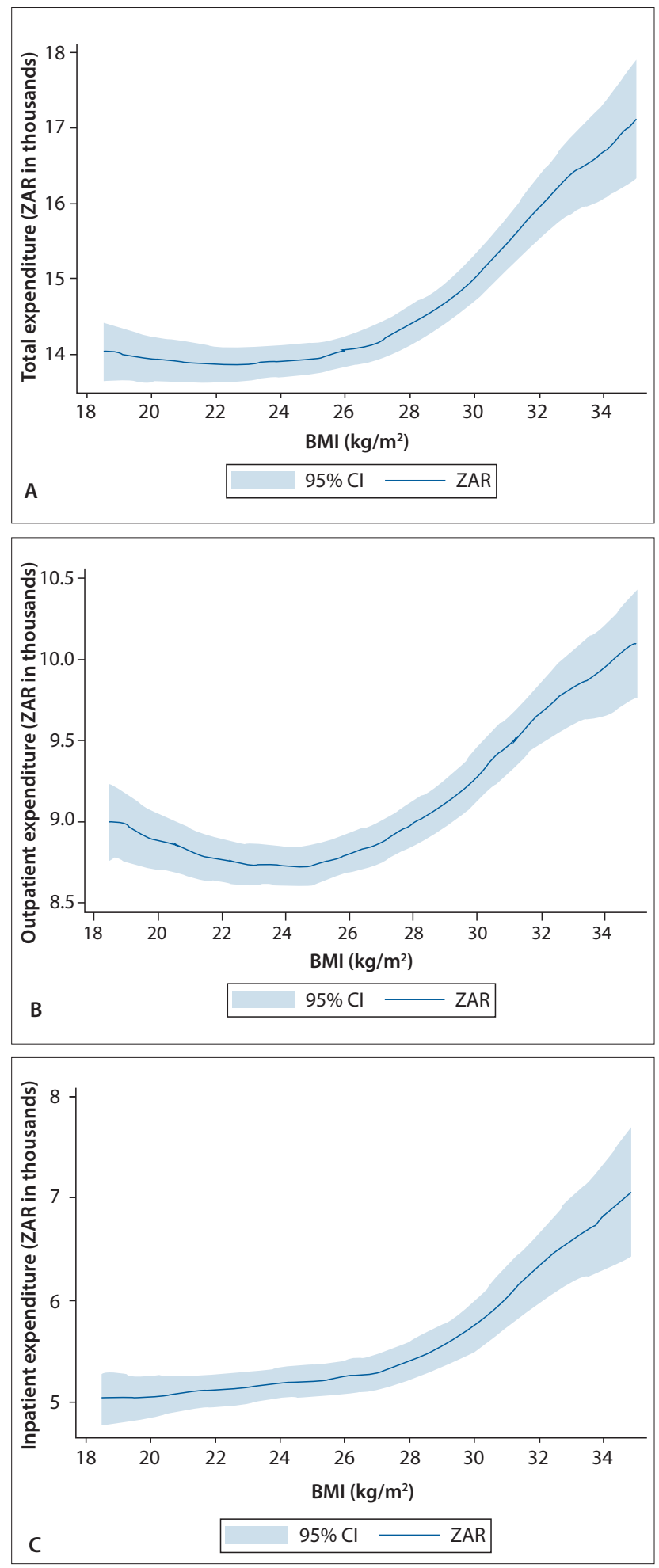

Fig. 1. (A) Total, (B) outpatient and (C) inpatient healthcare expenditure and body mass index (BMI) in 2010. Curves for BMIs $18.5-35 \mathrm{~kg} / \mathrm{m}^{2}$ are drawn because there are few observations in the underweight or severe obesity category for local estimates.

The health consequences of poor health habits are not instantaneous, are likely to depend on total exposure duration and may interact with ageing. This survey did not capture total exposure, e.g. years of smoking or years of obesity. Thus, the estimated cost consequences of health behaviours are population averages and likely to be smaller for individuals who are younger or have been exposed to a health risk for a shorter duration and higher for older individuals and longer exposures. While no measures of exposure (e.g. years of smoking, years of obesity) were available, we could estimate models stratified by age. When we restricted the analysis to individuals between 54 and 69 years of age, to parallel the US study by Andreyeva et al., ${ }^{[6]}$ moderate obesity increased expenditures by $21 \%$ for this age group (up from $11 \%$ for the full population), severe obesity by $51 \%$ (up from $23 \%$ ), and smoking by $20 \%$ (up from $13 \%$ ). This is comparable with the US estimates for this age group, where moderate obesity was associated with an increase of $25 \%$ and severe obesity with an increase of $\geq 50 \% .{ }^{[6]}$ In a meta-analysis of mortality studies, overweight was not associated with increased mortality rates, whereas higher levels of obesity were. It is expected that the association between obesity and healthcare costs would increase in middle age when chronic conditions caused by poor health behaviours tend to manifest, whereas high rates of obesity among younger cohorts would show their adverse impacts in the future.

The absence of a significant effect of excessive alcohol consumption may seem surprising since many believe that alcohol abuse has a large effect on healthcare costs, but is also consistent with evidence from other countries. ${ }^{[12,13]}$ There are important outcomes outside the scope of this analysis that might have provided a different ranking. Smoking may still account for more premature deaths and alcohol abuse is likely to account for more externalities (e.g. drunk-driving accidents). These results are based on a defined sample of health plan members who completed a health assessment and may therefore not be generalisable to all South Africans who are members of medical insurance plans (and obviously, do not apply to the majority of SA citizens who do not receive private healthcare). About one-third of the people sampled were current or past smokers and only $12 \%$ admitted to current smoking, with only a $1 \%$ point difference between men and women. In contrast, the 2003 South Africa Demographic and Health Survey (SADHS) ${ }^{[14]}$ reported current daily smoking rates of $>30 \%$ for men. For SA, the social impact of smoking would be larger than in our sample due to the high prevalence of smoking among the general population.

The 2003 SADHS objectively measured height and weight and reported an average BMI of $24 \mathrm{~kg} / \mathrm{m}^{2}$ for men and $27.2 \mathrm{~kg} / \mathrm{m}^{2}$ for women, corresponding to obesity rates of $14 \%$ and $30 \%$, respectively. Our data using self-reported height and weight are not directly comparable. In adjusting for the difference using alternative cut-off points based on US data, we estimate that $34 \%$ of men and $24 \%$ of women in our study would be classified as obese, based on objective measurements. This is more than double the rate for men in the 2003 survey, but less for women, indicating substantial differences in obesity prevalence by gender between our insured participants and uninsured South Africans.

Comparing our data with that of the US Behavioral Risk Factor Surveillance System (BRFSS), a national telephone survey that also used self-reported height and weight to calculate BMI, the mean BMI for US men in 2010 was $27.9 \mathrm{~kg} / \mathrm{m}^{2}$, corresponding to an obesity rate of $28 \%$. This is not very different from the average BMI of $27.7 \mathrm{~kg} / \mathrm{m}^{2}$ and an obesity rate of $24.4 \%$ for SA men in our sample. For women in 2010 , the BRFSS gave an average BMI of $27.1 \mathrm{~kg} / \mathrm{m}^{2}$ and an obesity rate of $26.5 \%$, compared with an average BMI of $25.6 \mathrm{~kg} / \mathrm{m}^{2}$ and an obesity rate of $18 \%$ in our sample.

For all health risks, whether smoking, problem drinking or obesity, a time lag exists between obesity and the development of chronic health problems. In the US, the largest decline in smoking rates happened between 1960 and 1980, whereas the largest increase in obesity has 
Table 2. Estimated change in healthcare expenditure and chronic conditions associated with specific behavioural risk factors - all age groups $(N=69380)^{*}$

\begin{tabular}{|c|c|c|c|c|}
\hline & \multicolumn{3}{|c|}{ Expenditure $(\mathrm{ZAR})$, mean $( \pm \mathrm{SD})$} & \multirow{2}{*}{$\begin{array}{l}\text { Count of chronic } \\
\text { conditions (max. } 17)\end{array}$} \\
\hline & Total & Outpatient & Inpatient & \\
\hline Ageing 10 years from 40 to 50 & $3204( \pm 594)^{5}$ & $3269( \pm 335)^{5}$ & $-60( \pm 420)$ & $0.27( \pm 0.0018)^{5}$ \\
\hline \multicolumn{5}{|l|}{ BMI $\left(\mathrm{kg} / \mathrm{m}^{2}\right)^{\dagger}$} \\
\hline$\geq 25-<30$ (overweight) & $140( \pm 360)$ & $-220( \pm 203)$ & $360( \pm 252)$ & $0.18( \pm 0.01)$ \\
\hline$\geq 30-<35$ (obese) & $2238( \pm 474)^{5}$ & $537( \pm 267)^{\ddagger}$ & $1700( \pm 335)^{5}$ & $0.41( \pm 0.01)^{5}$ \\
\hline$\geq 35$ (severely obese) & $4425( \pm 647)^{5}$ & $1909( \pm 364)^{5}$ & $2515( \pm 457)^{5}$ & $0.70( \pm 0.02)^{5}$ \\
\hline Current or past regular smoker & $2596( \pm 322)^{5}$ & $1301( \pm 182)^{\varsigma}$ & $1294( \pm 227)^{5}$ & $0.17( \pm 0.01)^{5}$ \\
\hline Heavy drinking & $-2022( \pm 1804)$ & $-1156( \pm 1016)$ & $-865( \pm 1274)$ & $0.34( \pm 0.05)^{5}$ \\
\hline
\end{tabular}

Table 3. Estimated change in healthcare expenditure and chronic conditions - 54 - 69 -year age group $(N=8765)^{*}$

\begin{tabular}{|c|c|c|c|c|}
\hline & \multicolumn{3}{|c|}{ Expenditure (ZAR), mean $( \pm \mathrm{SD})$} & \multirow{2}{*}{$\begin{array}{l}\text { Count of chronic } \\
\text { condition (max. 17) }\end{array}$} \\
\hline & Total & Outpatient & Inpatient & \\
\hline \multicolumn{5}{|l|}{$\mathrm{BMI}^{\dagger}$} \\
\hline$\geq 25-<30$ (overweight) & $1143( \pm 1521)$ & $651( \pm 737)$ & $491( \pm 1175)$ & $0.36( \pm 0.04)^{\ddagger}$ \\
\hline$\geq 30-<35$ (obese) & $6639( \pm 1972)^{\ddagger}$ & $1516( \pm 955)$ & $5122( \pm 1522)^{\ddagger}$ & $0.65( \pm 0.05)^{\ddagger}$ \\
\hline$\geq 35$ (severely obese) & $15835( \pm 2805)^{\ddagger}$ & $6946( \pm 1360)^{\ddagger}$ & $8889( \pm 2166)^{\ddagger}$ & $0.97( \pm 0.07)^{\ddagger}$ \\
\hline Current or past regular smoker & $6195( \pm 1340)^{\ddagger}$ & $3107( \pm 650)^{\ddagger}$ & $3087( \pm 1035)^{\ddagger}$ & $0.24( \pm 0.03)^{\ddagger}$ \\
\hline
\end{tabular}

occurred since 1980. In SA, the full consequences of increased obesity rates at the aggregate level are probably not yet visible.

Acknowledgments: Financial support was provided by the National Cancer Institute (grant no. R21CA161287) and the National Institute of Child Health \& Human Development (grant no. R21HD071568). We thank Derek Yach for comments on an earlier draft.

\section{References}

1. Mayosi BM, Flisher AJ, Lalloo UG, et al. The burden of non-communicable diseases in South Africa. Lancet 2009;374(9693):934-947. [http://dx.doi.org/10.1016/S0140-6736\%2809\%2961087-4]

2. Kengne AP, Echouffo-Tcheugui JB, Sobngwi E, et al. New insights on diabetes mellitus and obesity in Africa-Part 1: Prevalence, pathogenesis and comorbidities. Heart 2013;99:979-983. [http://dx.doi.org/ $10.1136 \% 2$ Fheartjinl-2012-303316

3. Peer N, Steyn K, Lombard C, et al. Rising diabetes prevalence among urban-dwelling black South Africans. PLoS One 2012;7(9):e43336. [http://dx.doi.org/10.1371\%2Fjournal.pone.0043336]

4. Peer N, Bradshaw D, Laubscher R, et al. Urban-rural and gender differences in tobacco and alcohol use, diet and physical activity among young black South Africans between 1998 and 2003. Glob Health Action 2013;6:19216. [http://dx.doi.org/10.3402\%2Fgha.v6i0.19216]
5. Reddy SP, Resnicow K, James S, et al. Rapid increases in overweight and obesity among South African adolescents: Comparison of data from the South African National Youth Risk Behaviour Survey in 2002 and 2008. Am J Public Health 2012;102(2):262-268. [http://dx.doi.org/10.2105\%2FAJPH.2011.300222] 6. Andreyeva T, Sturm R, Ringel JS. Moderate and severe obesity have large differences in health care costs. Obes Res 2004;12(12):1936-1943. [http://dx.doi.org/10.1038\%2Foby.2004.243]

7. Flegal $\mathrm{KM}$, Kit BK, Orpana $\mathrm{H}$, et al. Association of all-cause mortality with overweight and obesity using standard body mass index categories: A systematic review and meta-analysis. JAMA 2013;309(1):71-82. [http://dx.doi.org/10.1001\%2Fjama.2012.113905]

8. Hattori A, Sturm R. The obesity epidemic and changes in self-report biases in BMI. Obesity 2013;21(4):856-860. [http://dx.doi.org/10.1002\%2Foby.20313]

9. Sturm R, Hattori A. Morbid obesity rates continue to rise rapidly in the United States. Int I Obes Sturm R, Hatori A. Morbid obesity rates continue to rise

10. Manning WG, Mullahy J. Estimating log models: To transform or not to transform. J Health Econ 2001;20(4):461-494. [http://dx.doi.org/10.1016\%2FS0167-6296\%2801\%2900086-8]

11. Duan N, Manning WG, Morris CN, et al. A comparison of alternative models for the demand for medical care. J Bus Econ Stat 1983;1(2):115-126. [http://dx.doi.org/10.2307\%2F1391852]

2. Sturm R. The effects of obesity, smoking, and drinking on medical problems and costs. Health Aff 2002;21(2):245-253. [http://dx.doi.org/10.1377\%2Fhlthaff.21.2.245]

13. Polen MR, Green CA, Freeborn DK, et al. Drinking patterns, health care utilization, and costs among HMO primary care patients. J Behav Health Serv Res2001;28(4):378-399. [http://dx.doi.org/10.1007\%2FBF02287770] 14. National Department of Health. 2003 South Africa Demographic and Health Survey. Pretoria: NDoH 2003. http://www.info.gov.za/view/DownloadFileAction?id=90143 (accessed 5 June 2013).

Accepted 30 July 2013 